\title{
Evaluating the impact of the public library book collection: a case study of two public libraries in Cape Town
}

\author{
Janusz Skarzynski ${ }^{1}$ and Mary Nassimbeni² \\ janusz.skarzynski@capetown.gov.za ORCID: orcid.org/0000-0002-7963-4641 \\ mary.nassimbeni@uct.ac.za ORCID: orcid.org/0000-0002-7579-3880
}

\author{
Received: 04 July 2016 \\ Accepted: 01 August 2016
}

\begin{abstract}
This paper reports the preliminary findings of an investigation into the impact on a sample group of 100 respondents of using the book collection in two public libraries in Cape Town. It is particularly concerned with the benefits of leisure reading as measured through an impact study using a questionnaire based on generic learning outcomes as proposed by the Museums, Libraries and Archives Council of the United Kingdom. These outcomes cover the following domains: knowledge and understanding; skills; attitudes or values; enjoyment, inspiration and creativity; activity, behaviour or progression. The findings are presented and discussed and the conclusion is drawn that a range of benefits were experienced and reported in overwhelming numbers by the participants in the study.
\end{abstract}

Keywords: Public libraries, South Africa, leisure reading, impact evaluation

\section{Introduction}

In times of fiscal restraint and greater emphasis on accountability amongst all types of libraries, there are accelerating demands that libraries show evidence of their value. The South African library and information services sector is not immune from these pressures - the final draft of the Library and Information Services Transformation Charter contains a new chapter on monitoring and evaluation which argues that "LIS of all types should have a programme of monitoring and evaluation (M \& E) in the interests of good governance, accountability and the opportunity for the collection of evidence on their impact and value" (Nkondo et al. 2014: 107). Libraries across the globe will be assisted in their efforts to document and demonstrate impact through the timely publication of ISO 16439 Methods and procedures for assessing the impact of libraries (International Standards Organisation 2014) that will assist libraries in their efforts to document and demonstrate their value. ISO 16439 proposes various ways of assessing the impact of libraries, both academic and public. The methods described in the ISO standard for assessing library impact are useful and can generate the required data to evaluate the impact of a particular library. Much of the library impact literature tends to report, in general, on the effects of interactions between individuals and a particular library (Poll 2003), particularly in the academic library where there is a longer tradition of impact measurement than in the public library. The limited literature on the impact of collections investigates interactions between library users and electronic collections (for example, Spezi et al. 2013) rather than the use of particular print collections.

\section{The research problem}

Since $51 \%$ of South Africa's population does not own any leisure reading material (South Africa. Department of Arts and Culture 2006: 34), public libraries are the only source of this material for the majority of the population. The question arises, then: does the simple provision of leisure reading material (in the form of print collections) in public libraries have a positive impact on the lives of their communities?

In the academic library, the impact of the collection is potentially easier to discern because its constituencies are clearly defined, and the dimensions of use fall into contained areas of learning, teaching and research, which can be further categorised into disciplinary domains. The impact of the collection in the public library is far more difficult to uncover because of the diversity of its member groups and their varying roles, and the multiplicity of reasons for which the public library might be used. The use of the collection within a public library is not driven solely by informational, educational or research needs of the individuals, but in great part by the leisure reading pursuits of the people using the library. There has been very little research on this topic. The City of Cape Town libraries' spend on book collections is approximately R9 million annually (City of Cape Town. Library and Information Services 2016). The collections in the 102 public libraries in Cape Town consist of around 4.5 million books (City of Cape Town. Library and Information Services 2016).

1. Janusz Skarzynski is Principal Librarian, Fish Hoek, City of Cape Town Library and Information Services and is registered for the MPhil at the Library and Information Studies Centre, University of Cape Town. This paper reports on the preliminary findings from the MPhil

2. Mary Nassimbeni, corresponding author, is supervisor of Janusz Skarzynski's MPhil at the Library and Information Studies Centre, University of Cape Town 
In order to address this gap, the intention of this research was to evaluate the impact of the public library's book collection by undertaking a case study in two Cape Town public libraries. The goal of this research is set out in Table 1, adapted from Huysmans and Oomes (2012: 5), notably in the final outcome column. If one can show that the print collection of a public library can meet the goals listed in the final column of the table, then it can be concluded that individuals benefit from their use of the collection. The study was informed by its intention to uncover this benefit.

Table 1 Library mission, outputs and impact (adapted from Huysmans \& Oomes 2012:5)

\begin{tabular}{cccc}
\hline Library mission & Output (library does) & Output (library counts) & Outcome/Impact (hoped for) \\
\hline $\begin{array}{c}\text { Stimulate reading and } \\
\text { contribute to the level of } \\
\text { language skills }\end{array}$ & Collection (quantity and & People read the books they borrow \\
& quality) & Use of materials (count) & They were inspired/surprised \\
& & Reading skills improved & Perceptions changed \\
& & People want to read more
\end{tabular}

This paper briefly outlines the methodology used and reports on the preliminary results of the study.

\section{Literature review}

Performance measurement of the public library has been evolving in the last two decades. Its progress in public libraries is summarised by Huysmans and Oomes (2012) who discuss the move from output-based assessment of public libraries towards assessing the outcomes and impact of public library services. This trend in the public library sphere towards new standards for assessment has two basic drivers. The first, according to Poll and Payne (2006: 548), is a need to demonstrate to funders and politicians the benefit of providing a public library service. The second is the adoption of evidence-based assessment in the public library field according to Booth (2006). His paper explores the adoption of evidenced-based assessment in the public library sphere. This approach relies not just on counting the use of resources or services, but assessing the 'improvement' for the individuals who make use of the specific service.

Streatfield and Markless (2009) and the International Standards Organisation's (ISO) Standard 16439 (International Standards Organisation 2014) provide the definition of impact - relevant to this study - as the difference or change in an individual that results from intentional or accidental contact with a library service. If positive, change can be expressed as beneficial; an effect that is helpful or intended to be helpful. Value is "the importance that stakeholders (funding institutions, politicians, the public, users, staff) attach to libraries and which is related to the perception of actual or potential benefit" (International Standards Organisation 2014: 23).

With respect to methods for the collection of data to demonstrate impact, Streatfield and Markless point out that researchers are likely to need to ask questions of participants in order to infer change (2009: 137). This approach introduces an element of subjectivity that is inescapable in studies where no surrogate measurements are available such as pre- and post-tests associated with a specific intervention. ISO 16439 also refers to the challenge of relying on subjective data (International Standards Organisation 2014: 18), necessary in studies of a particular type where change can only be observed through self-reporting. Since the current study focuses on reading experiences, subjective data are integral to the purpose, as reading studies by Moyer (2007), Ross (2000) and Bray (2007) have shown.

The concept of 'leisure reading', defined by Clark and Rumbold (2006: 1) as reading that an individual does of his/her free will, underpins the study. Related terms are 'reading for pleasure', 'voluntary reading' and 'independent reading'. Nell (1988) and Holden (2004) refute the commonly-held perception that reading is a passive activity by pointing out its creative and interactive dimension. Author Pullman elaborates on the reader's active engagement with the text and relationship with the author:

Consider the nature of what happens when we read a book.... It isn't like a lecture: it's like a conversation. There's a back-and-forthness about it. The book proposes, the reader questions, the book responds, the reader considers. We bring our own preconceptions and expectations, our own intellectual qualities, and our limitations, too, our own previous experiences of reading, our own temperament, our own hopes and fears, our own personality to the encounter (Pullman 2004: n.p.).

The benefits of this type of reading are explained in the works of Krashen (2006) and Nell (1988) who have shown that reading for leisure benefits individuals by:

- $\quad$ increasing their level of literacy;

- improving their cognitive function;

- improving their emotional state of mind; and

- uplifting the individual economically, socially and educationally.

While it is difficult to quantify and identify the above, and it is possible for readers to be unaware of these changes (Nell 1988), studies conducted by Moyer (2007), Ross (2000) and Bray (2007) have demonstrated that it is possible to use surveys and interviews to identify learning that individuals experience during leisure reading. 


\section{Research methods}

Two public libraries in Cape Town were selected as sites for this research based on the comparable size of their print collections and the number of members using the library, thereby allowing for comparison of results. One of the libraries is located in a community that is predominantly English-speaking, where the majority of the adult population is either employed or retired (Library A), while the other library is located in a former township, where the population may have English only as a second language and where unemployment and economic uncertainty are more commonplace (Library B). Library A has a collection of approximately 50,900 items and circulates around 130,000 items annually among its 3,921 members. Library B's collection numbers 61,105 , while the annual circulation figure is 110,000 for 5,357 members (City of Cape Town Library and Information Services 2015). The selection of the two libraries serving differing communities allowed the influence of different conditions on reading behaviour to be uncovered.

Since the type and range of changes in the individual are subtle and largely internalised, the research methods had to involve direct feedback from the individual. In order to assess the direct impact of voluntary reading (as a result of making use of the public library's print collection), the identification of change in the individual is needed. Based on the research referred to above, the Generic Learning Outcomes (GLOs) can be used to identify the beneficial outcomes of voluntary reading (United Kingdom. Museums, Libraries and Archives Council 2008).

A short questionnaire (Appendix 1) was developed with questions that could be directly linked to the GLOs as developed by the United Kingdom's Museums, Libraries and Archives Council (2008). The GLOs all relate to an individual's perception of improvement as a result of his/her interaction with a museum, library or archive. These have been identified as:

- increase in knowledge and understanding;

- increase in skills;

- change in attitudes or values;

- evidence in knowledge;

- evidence of enjoyment, inspiration and creativity; and

- $\quad$ evidence of activity, behaviour, progression (United Kingdom. Museums, Libraries and Archives Council 2008).

Table 2 Survey questions and related outcomes

(GLO) Knowledge and understanding
Q. Reading has helped me understand why some people behave in a certain way
Q. I think that reading has allowed me to better understand historical events
(GLO) Attitudes and Values

Q. Reading has given me a better understanding about people who are different from me (belong to a different religion, culture or race)

Q. Reading has helped me deal with my emotions and feelings

(GLO) Skills

Q. Reading has improved how I communicate with other people (writing, speaking and listening)

Q. Reading has helped me to better understand what other people are feeling

(GLO) Enjoyment, inspiration and creativity

Q. I find reading an enjoyable part of my life

Q. Reading has inspired me to try something new

(GLO) Action, behaviour, progression

Q. Reading has made me change the way I do something in daily life

Q. Reading has helped me understand problems and solve them

(Moyer) Awareness of learning

Q. Reading has taught me very little

Q. Nothing I read relates to my life

Social practice

Q. I discuss the novels I read with my friends

Amount of reading

Q. How many books do you read on average in a month?

Table 2 shows how specific questions linked to a particular GLO were generated for the questionnaire, with the addition of a sixth outcome based on a study in the United States of America (USA) by Moyer (2007) who investigated learning through leisure reading. The question that follows reflects the recognition that reading is not merely an individual 
pursuit, but a social practice (Barton and Hamilton 2000: 7.) The final question sought to profile respondents with respect to the amount they read. Included in the questionnaire was an explanation of leisure reading to assist the participants in identifying that type of reading behaviour.

Convenience sampling was used and a questionnaire (see Appendix 1) was handed out by the lead researcher to willing adult participants at both sites at various times on different days over the period of two weeks. In all, fifty completed questionnaires from each site were collected. The questionnaire is attached as Appendix 1. The findings are discussed in Section 5.

An interview schedule has also been designed with the intention of probing particular trends emerging from the questionnaire. In addition, it seeks to gain an in-depth insight into the reading experience of the respondents by inviting them to articulate any relationship between particular books they have read and their lives. It will attempt to investigate the longevity of any particular effect of reading on a respondent's life, and invite them to express their attitude to reading and its role in their lives. Interviewees (five from each site) will be selected from survey participants who volunteered their contact information when asked if they would be willing to be interviewed, twenty-two from Library A and thirty-one from Library B.

\section{Findings and Discussion}

The participants in the survey from both libraries fall into a similar age profile, with only small differences between the higher number of younger participants at Library B and older participants at Library A. These differences are reflected in the demographics of the communities as the suburb Library A serves has double the percentage of residents over the age of sixty-five, as does the suburb surrounding Library B (City of Cape Town. Geographic Information System Department. 2013).

The number of books read in an average month as reported by the respondents was similar, with a slightly higher probability of more books being read per month by the users of Library A. The average for Library A is 6.48 books per month, while for Library B it is 6.15 books per month. Using the most recent survey of reading habits in the USA, the average intensity of reading in both libraries can be classified as heavy:

Roughly three in ten are light readers (one to five books in the past twelve months); another $25 \%$ to $31 \%$ are moderate readers (six to twenty) and just about two in ten are heavy readers (twenty-one or more books) in the past twelve months (Miller, Purcell \& Rainie 2012: n.p.).

The question asking whether the respondents discussed books they read with others was seen as a way of gauging if people had internalised what they had read. A large majority at both libraries reported in the affirmative: $88 \%$ at Library A and $90 \%$ at Library B. These percentages can be viewed as a sign that the participants in the survey are internalising what they are reading to an extent to which they are able to report on it. This is evidence of a positive link between reading and learning and supports the idea that reading is also a social practice that is situated in a particular context (Barton \& Hamilton 2000).

As far as the primary source of reading material is concerned, the participants from both libraries sourced the majority of their reading matter from libraries: $86 \%$ from Library A and $80 \%$ from Library B (question 6 of the questionnaire, Appendix 1). For the participants in this study, the public library is clearly the primary source of reading material, with a small balance of their reading material being sourced elsewhere. With respect to respondents' age, reading volume and the library as a source of reading material, the patterns of responses are fairly similar between the two libraries.

The next portion of the questionnaire asked participants to indicate their preferred genres, as listed in the questionnaire (See question 5, Appendix 1). This question was included both to gauge reading interests and to probe a possible link between reading benefits and a particular genre. Crime novels, thrillers, biographies and do-it-yourself books were the most popular genres at Library $\mathrm{A}$, while religious fiction, historical fiction, thrillers, crime novels and books on health were the most popular at Library $\mathrm{B}$. We have chosen the romantic fiction genre as an example to explore the link with GLOs, as set out in Table 3 and in Table 4.

Some of these results proved rather intriguing. For example, there is evidence of a stronger link in Library A between those who read romance and seven corresponding GLO statements, in comparison to those who do not like this genre (see Table 3). Those who do not read romance in Library A score higher on two GLOs (see Table 3). In Library B, the reading of romance is marginally less popular than in Library A (by two respondents), where those who do not like romance score higher than those who do in five out of nine GLOs (see Table 4).The GLO referring to feeling and emotions scored highly at both libraries amongst fans of romance fiction.

At both sites, the participants who enjoyed biographies all indicated positively for all the GLOs, in most cases $100 \%$ of them reported that learning related to the corresponding GLO had taken place. Those who did not read biographies tended to show some negative responses. The suggestion emerging from these data is that, for the most part, genre preference does not impact the perceived learning experience of leisure reading strongly but that there is some influence that seems to be localised. This would need to be studied further before any conclusion can be drawn.

When responding to the eleven questions directly relating to the GLOs, the majority of respondents from both libraries agreed with the statements that they had achieved learning outcomes as listed. These outcomes were: knowledge and understanding; attitudes and values; skills; enjoyment; inspiration and creativity; and action, behaviour, progression. 
Table 3 Relationship in Library A between the reading of romance fiction and GLOs

\begin{tabular}{|c|c|c|c|c|c|c|}
\hline \multirow{2}{*}{$\begin{array}{l}\text { Library A } \\
\text { Statements based on GLOs }\end{array}$} & \multicolumn{3}{|c|}{ Love Romance ( $\mathrm{N}=13)$} & \multicolumn{3}{|c|}{ Don't Read Romance ( $\mathrm{N}=14)$} \\
\hline & Agree & Don't Know & Disagree & Agree & Don't Know & Disagree \\
\hline $\begin{array}{l}\text { Reading has helped me understand why some } \\
\text { people behave in a certain way }\end{array}$ & 11 & 1 & & 11 & 2 & 1 \\
\hline $\begin{array}{l}\text { Reading has made me change the way I do } \\
\text { something in daily life }\end{array}$ & 11 & 1 & 1 & 8 & 3 & 3 \\
\hline $\begin{array}{l}\text { Reading has given me a better understanding of } \\
\text { people who are different from me }\end{array}$ & 11 & 1 & 1 & 13 & & 1 \\
\hline $\begin{array}{l}\text { Reading has improved my communication skills } \\
\text { with other people }\end{array}$ & 13 & & & 13 & 1 & \\
\hline $\begin{array}{l}\text { Reading has helped me to better understand what } \\
\text { other people are feeling }\end{array}$ & 10 & 1 & 1 & 11 & 2 & 1 \\
\hline Reading has inspired me to try something new & 11 & 1 & 1 & 11 & 2 & 1 \\
\hline $\begin{array}{l}\text { Reading has helped me deal with my emotions } \\
\text { and feelings }\end{array}$ & 9 & 1 & 1 & 9 & 3 & 2 \\
\hline $\begin{array}{l}\text { Reading has helped me understand problems and } \\
\text { solve them }\end{array}$ & 10 & 3 & & 9 & 3 & 2 \\
\hline $\begin{array}{l}\text { I think that reading has allowed me to better } \\
\text { understand historical events }\end{array}$ & 10 & 3 & & 13 & & \\
\hline
\end{tabular}

Two questions were allocated to test for each of the GLOs listed above and the options of 'agree', 'do not know' and 'disagree' were offered as answers. For the GLO of knowledge and understanding, the following statements were posed: "reading has helped me understand why some people behave in a certain way" and "I think that reading has allowed me to better understand historical events". A high percentage of participants from both libraries agreed with this: $90 \%$ and $89 \%$ respectively.

Table 4 Relationship in Library B between the reading of romance fiction and GLOs

\begin{tabular}{|c|c|c|c|c|c|c|}
\hline \multirow{2}{*}{$\begin{array}{l}\text { Library B } \\
\text { Statements based on GLOs }\end{array}$} & \multicolumn{3}{|c|}{ Love Romance $(\mathrm{N}=14)$} & \multicolumn{3}{|c|}{ Don't Read Romance ( $\mathrm{N}=16)$} \\
\hline & Agree & Don't Know & Disagree & Agree & Don't Know & Disagree \\
\hline $\begin{array}{l}\text { Reading has helped me understand why some } \\
\text { people behave in a certain way }\end{array}$ & 11 & 1 & 1 & 14 & 2 & \\
\hline $\begin{array}{l}\text { Reading has made me change the way I do } \\
\text { something in daily life }\end{array}$ & 11 & 2 & 1 & 14 & 1 & 1 \\
\hline $\begin{array}{l}\text { Reading has given me a better understanding of } \\
\text { people who are different from me }\end{array}$ & 13 & 1 & & 14 & 1 & 1 \\
\hline $\begin{array}{l}\text { Reading has improved my communication skills } \\
\text { with other people }\end{array}$ & 12 & 2 & & 15 & 1 & \\
\hline $\begin{array}{l}\text { Reading has helped me to better understand what } \\
\text { other people are feeling }\end{array}$ & 12 & 2 & & 14 & 2 & \\
\hline Reading has inspired me to try something new & 13 & & 1 & 15 & 1 & \\
\hline $\begin{array}{l}\text { Reading has helped me deal with my emotions } \\
\text { and feelings }\end{array}$ & 14 & & & 12 & 2 & 2 \\
\hline $\begin{array}{l}\text { Reading has helped me understand problems and } \\
\text { solve them }\end{array}$ & 12 & 2 & & 13 & 3 & \\
\hline $\begin{array}{l}\text { I think that reading has allowed me to better } \\
\text { understand historical events }\end{array}$ & 12 & 1 & 1 & 15 & 1 & \\
\hline
\end{tabular}

It was much the same with the response to the statements, "reading has given me a better understanding about people who are different from me" and "reading has helped me deal with my emotions and feelings". These statements were designed to test for changes in the GLO of attitudes and values. Library A participants were slightly less emphatic in their response to these questions, with $83 \%$ at Library $\mathrm{A}$ and $88 \%$ at Library $\mathrm{B}$ agreeing with the statements.

With respect to the statements referring to the GLO for skills, "reading has improved my communication skills with other people" and "reading has helped me to better understand what other people are feeling", $90 \%$ at Library A and $89 \%$ at Library B agreed.

The responses to the statements, "reading has made me change the way I do something in daily life" and "reading has helped me understand problems and solve them", are the only ones that show a noticeable shift in agreement at Library A, with those agreeing dropping below $80 \%$ to $78 \%$, while at Library B agreement remained high at $83 \%$. This 
result could be a reflection of how the different demographic, environmental and cultural factors between the two communities shape people's behaviour and actions.

The set of statements that referred to recognising if learning had taken place acted as 'trap questions'. The questions were added to check for respondents' awareness of learning and to test that they were reading the questions accurately. These two questions needed to be answered in the negative, as opposed to the other questions in the survey; thus, were 'trap questions', employed to test the respondents' attentiveness and consistency. Testing is done in a few selected questions by re-ordering the expected sequence of text, expressing statements in the negative after a string of positive statements (Smith 2013). The statements posed were "reading has taught me very little" and "nothing I read relates to my life". Fortunately, the responses were unquestionably in the negative, with Library A at $89 \%$ and Library B at $81 \%$, showing a strong awareness that leisure reading does contribute to the participants' learning.

The final portion of the survey was an open-ended question asking participants to name a book that had influenced their lives and to state why. At Library A, twenty-nine participants answered this question with the results broken down as follows:

- twelve respondents indicated novels;

- seven, general non-fiction;

- three, biographies;

- three, religious non-fiction;

- two, Christian fiction; and

- two, the Bible.

In general, the comments about the novels focused on learning about other people's perceptions and cultures. General non-fiction books tended to be about self-help or learning a skill. Religious books, collectively, made up one of the largest groupings: seven respondents.

The following comment mirrors many of the comments made about novels:

Helped me realise you always have to look at things from the other side. (A comment about To kill a mockingbird by Harper Lee)

A number of participants singled out non-fiction books with a Christian theme, usually offering some form of advice for overcoming setbacks in life or dealing with grief. Biographical or autobiographical books did not seem to have the same impact, and the comments tended to focus more on events reported in the books rather than on the individual themselves.

At Library B, thirty-one responded to the question above, though some of the titles were difficult to categorise. The following pattern emerged:

- $\quad$ thirteen respondents indicated novels;

- six, general non-fiction;

- three, biographies;

- three, religious non-fiction;

- $\quad$ three, the Bible; and

- two, periodicals.

The remaining book title could not be categorised. The breakdown of novels tended more towards family-based drama or romance and, similar to Library A, the comments referred to learning about other cultures and other people's points of view. More of the respondents from this library mentioned how the books impacted directly on their lives, for example:

It mirrors the type of life I have led which prompted me to write my own book. (A comment on Of human bondage by W. Somerset Maugham)

One comment mentioned how books with gay protagonists helped the participant in the survey come to terms with his sexual orientation. As with Library A, most of the non-fiction mentioned had religious themes. Crime novels featured twice and one isXhosa novel, unfortunately with no explanation as to the reason why. Interestingly, the novel Shantaram by Gregory David Roberts, which vividly describes life in Mumbai, appears on both lists, as does Nelson Mandela's autobiography, A long walk to freedom.

Taking into account the data collected at both sites, it would appear that there is very little difference in the learning that appears to take place between the participants from the two libraries. It would seem that these public libraries provide comparable learning opportunities to people from the differing communities. The benefit gained from the provision of the print collection is dependent on its use, however. Only one participant in the survey indicated not using books from the library. It would appear that, in general, use of a public library translates to significant and heavy use of the print collection. 
Unfortunately, employing surveys and the GLOs to assess learning does not allow for reflection on the nuances of the learning that took place. It is hoped that the proposed interview stage of the research will build a more complete picture of the level and degree of effects.

\section{Conclusion}

While there is still a fair amount of additional work needed to complete this study, and taking into account the small sample size (100 in total), it would appear that, following the guidelines of the ISO standard 16439 and the principles of impact assessment, it is possible to construct a viable research instrument that can demonstrate the benefits of leisure reading. The benefits reported in high numbers reflect and confirm the reading experience reported in a number of studies (for example, Krashen 2006, Clark and Rumbold 2006). Some aspects still need to be explored further, such as whether communities where English and Afrikaans (the two major languages in the collections in the two libraries) are not the primary language experience the same outcomes from the provision of a print collection, and how the use of the library relates to the benefit of the larger community. An attempt should be made to arrive at a better understanding of the type and level of learning taking place to enable a deeper understanding of the effects of reading in public libraries in diverse communities.

There is greater scope for public libraries to promote reading by adults in a more purposeful and programmatic way. Hartley and Turvey (2001) have documented a growing phenomenon: that of reading groups (a concept that includes the South African version of book clubs). They note that some of these groups meet in libraries while operating on the same principles and formats of most book clubs: members choose the book/s to be read, and their meetings involve discussion of the book/s in question. The public library in South Africa is an ideal venue for such groups, thus harnessing the momentum of this popular contemporary phenomenon and offering the opportunity for a social setting and social exchange, important aspects of the reading experience (Barton and Hamilton 2000).

Lessons for recruiting adults to public libraries for the purpose of highlighting the pleasures of reading can be drawn from the pioneering collaboration between an independent bookshop in Cape Town and two township public libraries to mark World Book Day in 2016. On 22 April 2016, ahead of World Book Day, the Book Lounge arranged for prize-winning author, Nic Mhlongo, to launch his new collection of short stories, Tales of affluenza, in the new library at Kuyasa in Khayelitsha and, the following day, in another township public library (Sloman \& Hudson 2016).

Public libraries need to market the undeniable benefit of leisure reading to elevate it to an activity of choice amongst members of their immediate communities, by offering book launches and discussions, author appearances and other reading activities. Innovative methods will be required in a country with low literacy rates and a scarcity of titles available in indigenous languages, building on advances made in the field of the promotion of children's reading evidenced in the work done in partnership with libraries of non-governmental organisations such as, for example, of Nal'ibali and Biblionef (see www.nalibali.org and www.biblionef.org.za). It is through the continued demonstration of public libraries' contribution to the broader society and lowering barriers of access to public libraries and their collections that print collections will continue to have relevance and make a contribution to the government's vision of a reading nation.

\section{Acknowledgements}

The authors acknowledge and wish to thank the National Research Foundation (NRF) of South Africa for their financial support of this research project.

\section{References}

Barton, D. and Hamilton, M. 2000. Literacy practices. In Situated literacies: reading and writing in context. D. Barton, M. Hamilton and R. Ivanic. London: Routledge. 7-14.

Booth, A. 2006. Counting what counts: performance measurement and evidence-based practice. Performance Measurement and Metrics, 7(2): 63-74. [Online]. http://www.emeraldinsight.com/10.1108/14678040610679452 (24 September 2010).

Bray, C. 2007. Libraries inspire learning: opening up the reading experience. [Online]. www.devon.gov.uk/reading_a_difference___pljsummer07pp15-16.pdf (8 March 2015).

Clark, C and Rumbold, K. 2006. Reading for pleasure: a research overview. London: National Reading Trust. [Online]. http://www.literacytrust.org.uk/assets/0000/0562/Reading_pleasure_2006.pdf (23 June 2016).

City of Cape Town. Geographic Information System Department. 2013. 2011 Census. [Online]. http:www.capetown.gov.za/en/stats/Pages/Census2011.aspx (3 July 2016).

City of Cape Town. Library and Information Services. 2016. About Us. [Online]. http://www.capetown.gov.za/en/Library/Pages/About-Us.aspx (30 June 2016).

City of Cape Town. Library and Information Services. 2015. Internal report for use by librarians. (Unpublished).

Hartley, J and Turvey, S. 2001. The reading groups book. Oxford: Oxford University Press.

Holden, J. 2004. Creative reading. London: Demos.

Huysmans, F. and Oomes, M. 2012. Measuring the public library's societal value: a methodological research program. Paper presented at the 78th IFLA General Conference and Assembly. 11-17 August 2012. Helsinki, Finland. [Online]. http://www.ifla.org/past-wlic/2012/76-huysmans-en.pdf (17 July 2014).

International Standards Organisation. 2014. ISO 16439 - Information and documentation - Methods and procedures for assessing the impact of libraries. Geneva: ISO Copyright Office. 
Krashen, S. 2006. Pleasure reading. Young Learners Special Interest Group, Spring: 2-4. [Online] http://www.educ.ualberta.ca/staff/olenka.bilash/best\%20of\%20bilash/Stephen_Krashen\%20pleasure\%20reading.pdf (27 April 2015).

Miller, C., Purcell, K. and Rainie, L. 2012. Reading habits in different communities. Washington, DC: Pew Internet. [Online]. http://libraries.pewinternet.org/files/legacy-pdf/LibrariesAndReading_CommunityTypes_12.20.12.pdf (27 June 2016).

Moyer, J. E. 2007. Learning from leisure reading: a study of adult public library patrons. Reference \& User Services Quarterly, 46 (4): 66-79. [Online]. http://www.jstor.org/stable/20864750 (29 September 2015).

Nell, V. 1988. Lost in a book: the psychology of reading for pleasure. New Haven: Yale University Press.

Nkondo, M., Brown, A., Dick, A., Hart, G., Molawa, S., Nassimbeni, M., Seleti, Y. and Teffo, L.J. 2014. The Library and Information Services (LIS) Transformation Charter. Pretoria: Department of Arts and Culture (DAC) and the National Council for Library and Information Services (NCLIS). [Online]. http://www.nlsa.ac.za/Downloads_01/2014_Final_LIS_Transformation_Charter.pdf (23 June 2016).

Poll, R. 2003. Impact/outcome measures for libraries. Liber Quarterly, 13 (3/4). [Online]. https://www.liberquarterly.eu/articles/10.18352/lq.7446/ (19 August 2015).

Poll, R. and Payne, P. 2006. Impact measures for libraries and information services. Library Hi Tech, 24(4): 547-562. [Online]. http://www.emeraldinsight.com/10.1108/07378830610715419 (19 August 2015).

Pullman, P. 2004. The war on words. Guardian Review. 6 November. [Online]. https://www.theguardian.com/books/2004/nov/06/usa.politics (19 June 2016).

Ross, C. 2000. Finding without seeking: what readers say about the role of pleasure reading as a source of information. Aplis, 13 (2): 72-80.

Smith, S. 2013. 4 ways to ensure valid responses to your online survey. [Online]. https://www.qualtrics.com/blog/onlinesurvey-valid-responses/ (12 August 2016).

Sloman, M. and Hudson, P. 2016. Pippa speaks to Mervyn Sloman of the Book Lounge. [Radio interview]. CapeTalk, Cape Town, 22 April. [Online]. http://www.capetalk.co.za/articles/13066/libraries-are-essential-in-a-country-wherebooks-are-so-pricey (14 July 2016).

South Africa. Department of Arts and Culture. 2006. Project book worm: national survey into the reading and book reading behaviour of adult South Africans. [Online]. http://www.sabookcouncil.co.za/sabookcouncil/pdf/NRSDOCopt.pdf (5 April 2015).

Spezi, V., Creaser, C., O'Brien, A. and Conyers, A. 2013. Impact of library discovery technologies: a report for UKSG. Loughborough: University of Loughborough. [Online]. http://www.uksg.org/sites/uksg.org/files/UKSG_final_report_16_12_13_by_LISU.pdf (19 June 2016).

Streatfield, D. and Markless, S. 2009. What is impact assessment and why is it important? Performance Measurement and Metrics, 10(2): 134-141. [Online]. http://www.emeraldinsight.com/10.1108/14678040911005473 (29 May 2015).

United Kingdom. Museums, Libraries and Archives Council. 2008. More about the generic learning outcomes. [Online]. http://www.big.uk.com/Resources/Documents/events/Little\%20Event/Generic\%20Learning\%20Outcomes\%20\%20example\%20statements.pdf (1 April 2015). 


\section{Appendix A}

\section{Assessing the impact of a public library's print collection: a case study of two public libraries in Cape Town}

I am Janusz Skarzynski, an M Phil student in the Library and Information Studies Centre, University of Cape Town. I would be most grateful if you could take the time to complete this questionnaire. The subject of this research is the outcome of leisure reading for individuals. Your answers will be treated confidentially. There are no right or wrong answers. Your participation in this study is voluntary. If you do not want to participate, please return the questionnaire to a library staff member. You also do not have to answer any questions that make you uncomfortable. The results of this study could help improve the library service by informing libraries on the types of books to stock. Please place your completed questionnaire in the box provided. My research is being funded by the National research Foundation (NRF), and is being supervised by Dr Mary Nassimbeni (mary.nassimbeni@uct.ac.za).

Leisure reading is the type of reading that a person does for no other reason than they want to. It is a voluntary activity and not required for study or school and can be fiction (novels) or non-fiction.

\section{Questions}

Please tick or mark the appropriate box:

1. I find reading an enjoyable part of my life

Agree

3. What Year were you born? 19

4. Do you discuss the books you read with other people?

Yes

No

5. What types of books do you like please tick the response next to each that is closest to your opinion i.e. Love, OK or Do Not Read

\begin{tabular}{|c|c|c|c|}
\hline & Love & OK & Do Not Read \\
\hline Romance & Love & OK & Do Not Read \\
\hline Religious fiction & Love & OK & Do Not Read \\
\hline Historical fiction & Love & OK & Do Not Read \\
\hline Crime fiction & Love & OK & Do Not Read \\
\hline Thriller/action fiction & Love & OK & Do Not Read \\
\hline Fantasy fiction & Love & OK & Do Not Read \\
\hline Science fiction & Love & OK & Do Not Read \\
\hline Biographies or Autobiographies & Love & OK & Do Not Read \\
\hline Health (non-fiction) & Love & OK & Do Not Read \\
\hline DIY or Home and Garden (non-fiction) & Love & OK & Do Not Read \\
\hline Inspirational/self-help (non-fiction) & Love & OK & Do Not Read \\
\hline SAthetribs\&9ks suchchops:82(1) & Love & OK & Do Not Read \\
\hline
\end{tabular}

6. Please tick the statement that applies to you:

The public library provides me with:

All the books I read

More than half the books I read

$\square$ None of the books I read 


\begin{tabular}{|c|c|c|c|}
\hline \multicolumn{4}{|c|}{$\begin{array}{l}\text { 7. Please read the statements below and tick the response in the adjoining column that is closest to your opinion } \\
\text { (i.e. Agree, I do not know, Disagree) }\end{array}$} \\
\hline 7.1 Reading has helped me understand why some people behave in a certain way & Agree & I do not know & Disagree \\
\hline 7.2. Reading has made me change the way I do something in daily life & Agree & I do not know & Disagree \\
\hline $\begin{array}{l}\text { 7.3. Reading has given me a better understanding of people who are different from me } \\
\text { (follow a different religion, culture or race) }\end{array}$ & Agree & I do not know & Disagree \\
\hline 7.4. Reading has taught me very little & Agree & I do not know & Disagree \\
\hline $\begin{array}{l}\text { 7.5. Reading has improved my communication skills with other people (writing, } \\
\text { speaking and listening) }\end{array}$ & Agree & I do not know & Disagree \\
\hline 7.6. Reading has helped me to better understand what other people are feeling & Agree & I do not know & Disagree \\
\hline 7.7. Reading has inspired me to try something new & Agree & I do not know & Disagree \\
\hline 7.8. Nothing I read in relates to my life & Agree & I do not know & Disagree \\
\hline 7.9. Reading has helped me deal with my emotions and feelings & Agree & I do not know & Disagree \\
\hline 7.10. Reading has helped me understand problems and solve them & Agree & I do not know & Disagree \\
\hline 7.11. I think that reading has allowed me to better understand historical events & Agree & I do not know & Disagree \\
\hline
\end{tabular}

8. Please name a leisure reading book (a book that you read for no other reason than you wanted to; not for study or school) that has greatly influenced your life. Please elaborate on how this book has impacted your life.

As part of my research, I will be conducting voluntary follow-up interviews where I will ask more questions about reading experiences. Please provide an email address and/or telephone number if you would be interested in being interviewed. I would appreciate hearing your views.

Email: Phone number: 